\title{
Learn, Teach and Share, Participation in Expanded Educational Communities: Madrid Pikler Seminar as a Practice of Continuing Education between Childhood Professionals
}

\author{
Javier González-Patiño \\ javier.gonzalezpatino@uam.es \\ Universidad Autónoma de Madrid, Spain
}

\begin{abstract}
This article analyzes an expanded learning experience, expanded in the sense that this experience is mediated by public digital space, in which a very active collective of educators that work with young children strive to improve their professional practice incorporating the pedagogical approaches of Emmi Pikler. Although, initially, the format of this seminar was based on discussion and analysis meetings, a few years back the author and researcher joined to suggest open and connected activities, promoting the use of standard tools of the social web that enable participants to create knowledge before, during and after the sessions; as well as disseminate, debate and recover it afterwards. The interpretation and analysis of this experience showcase the diversity and evolution of the trajectories of participation that take place within this community of practice, and the design of its functional elements and protocols intend to inspire an expanded approach in other learning scenarios.
\end{abstract}

\section{Keywords}

Community of practice; connected learning; public digital space; legitimate peripheral participation; learning trajectories; digital media and learning; participatory culture. 


\section{Introduction}

The uses and practices of technologies applied to learning that emerge in the form of different semiotic mediation styles as result of participatory-communicative processes involve complex interactive transformations of spaces (González-Patiño, 2011). From a systematic standpoint, and taking into consideration digital space, both public and private, media and technology enable certain mutual inclusions, which could be symbolically snatched from this virtual space, as long as the possibilities and decisions the participants and agents involved allow it (educational ideologies, legal limitations, conventions, institutions, community, etc.). Both in contexts related to learning and knowledge as well as other less regulated contexts where people enjoy the necessary autonomy to build and display their social and cultural identity.

This possibility of symbolic conversion of the digital that enables appropriations and inclusions of geolocalized spaces (work, home, school, etc.), due to the development of computer and communication technologies, gives way to another peculiarity specific to the field work of the present investigation: it becomes, with certain frequency, the scenario for reflective practices and knowledge production (Gee, 2013). Complementary to the studies that explore institutionalized and recognizable contexts through an easily identifiable location, this study is situated in the intersection of these places, in an exercise of collaborative, participatory and transformative approaches that offer a large part of the total data.

Although part of the debate in public opinion on educational reform stemming from the impact of technology is centered on learning and evaluating with certain narrow mindedness (issues such as the adaptation and personalization of teaching), academics and experts propose the creation of emerging areas of interest that could articulate research and the creation of transdisciplinary knowledge, such as Digital Media and Learning (Gee, 2010) or Connected Learning (Ito et al., 2013), that allow us to consider technological developments as included and situated in a society in deep and accelerated transformation. It would be hard to imagine a better historical moment to aspire to educational change for social justice than the present one, of media convergence, lived by a hyper-connected society (Van Dijck, 2013) that is transforming the uses of communication media, through the rise of participatory culture, and building new styles of democratization of learning and creation of content (Jenkins, 2008; Jenkins, Ford, \& Green, 2013).

Action research, therefore, appears as a relevant approach for a study such as this one (Noffke \& Somekh, 2013; Reason \& Bradbury, 2008) based on practices that support a long-term view of education, shifting away from what has been up until now the dominant model of searching for and proposing the "Best Practices", and is coming to a more respectful model of "Pretty Good Practices" (Erickson, 2014) that aims to incorporate the agency and autonomy of each educational community expanded by this digital empowerment. Consequently, a lot of importance has been granted to innovation coming from social and cultural practices of a community constituted with the aim to explore and research the impact of said practices.

Likewise, it is important to stress that the interest of the participants in this community is based on the improvement of a professional practice that takes place in regulated places of learning (the majority work in public preschools and kindergartens) and even so they have presented this eminently located learning activity, legitimizing it through identity and peripheral participation dynamics, typical of communities of practice (Lave \& Wenger, 1991; Wenger, 2005; Wenger, McDermott, \& Snyder, 2002), and establishing a connection between formal and informal contexts of different ecosystems, such as education and culture (Cobo \& Moravec, 2011).

However, the dissemination and scope that the notions of participatory culture and community of practice have achieved recently in academic and professional debates, and specifically in educational research, should inspire us to critically revise how this success has affected the central values that prompted the first years of situated learning and participatory culture theory, which 
focused on professional communities that were relatively defined, face to face, such as tailors (Lave, 2011), butchers (Lave \& Wenger, 1991) and Xerox technicians (Orr, 1996). We should ask ourselves what it means to apply those ideas regarding learning and participation in school, online communities or in work groups in businesses (Jenkins, Ito, \& boyd, 2015).

\section{a. Connected Learning in the Digital Culture Society}

While some authors argue that we find ourselves at the birth of a utopia where communication mediated by technology will definitely change our thinking and the way we acquire knowledge, there are plenty of skeptics that warn us of the damaging effects of Internet, arguing that it is turning us more superficial by altering our capacity to concentrate and reflect. We are witnessing an epistemological confrontation where connectivism (Siemens, 2010) is met with critical voices that put into question that technical changes have modified, in an essential manner, the principles of learning beyond certain required procedural transformations in education (Carr, 2011).

Although the main function of formal education - to help build psychological tools that enable people's life projects and socialization - has not changed, there is a pressing need for a deep reflection on the model of student to whom it is directed, at least, and to the very sense of the institution, as well as the articulation and connection of formal educational practices, as opposed to the experiences of informal learning. Education is a social invention (Bruner \& Palacios, 2008), therefore, it will manifest different degrees of imbalance with the society in which it takes place, since society changes and evolves and requires it to incessantly adapt. Formal education in the connected society must take into account the coordinates of this new ecology of learning (Coll, 2013), as well as the connection between teaching practices and experiences that occur outside the institution that legitimizes them.

The analysis of this expanded and participatory practice, born out of an action research initiative, intends to reflect on the bases of connected learning, characteristic of the digital culture, that considers the diverse as a requisite for efficiency and sustainability, and where the student is considered a co-designer (legitimate peripheral participation) of learning, understood as a situated and crucial activity in our current society of knowledge (Ito et al., 2013; Kalantzis \& Cope, 2012).

Our ultimate goal is to offer a positioning for the expert practice and research, a personal proposal of accompanying and experimentation with educational communities, with a methodological approached based on action research and a manner of involvement based on participatory consultancy (Wardrop \& Withers, 2014). To be more specific, this is an operative and applied approach to the development of the Seminar Pikler Madrid, an expanded educational community created on the basis of a community of active practice, through a collaboration that expands more than four years with the Asociación Española de Escuelas Infantiles de Gestión Indirecta (AMEIGI), Universidad Autónoma de Madrid (UAM) and Medialab-Prado Madrid.

\section{Method: Creating an Expanded Educational Community}

The learning experience that is under analysis in this publication is a participatory activity created with the intention of proposing a space for continued learning for preschool and kindergarten education professionals of the Autonomous Community of Madrid. Participatory action research (PAR) inseparably combines the creation of knowledge and social intervention (Regina Frizzo, 2008). It is a way of conceiving research in which the participation in the process of the observed subjects, is considered an opportunity to promote their understanding of their social reality with the intention of transforming it collectively. Although formerly the PAR is identified with a militant activism taking position in favor of oppressed groups, from the $80 \mathrm{~s}$, to the contributions of social and community psychology will join those of other researchers with different interests, 
strengthening even more this methodological orientation (Balcazar, 2003). It is precisely within this framework in which this work would be situated, and the most relevant conceptual aspects taken into account are:

- Legitimize social and cultural practices as an element to generate scientific knowledge, both to identify problems or research questions and to propose solutions.

- Eliminate the separation between researcher and participant, since only through the interaction between both is the investigation and intervention process possible.

- Produce changes both in the situation (educational practice) and in the participants and researchers (community of practice, knowledge produced and established relationships), as a result of a continuous process of action-reflection.

This initiative, supported by AMEIGI, is a self-organized activity lead by an active collective, composed in large part by young educators that work in public preschools and kindergartens, to deepen their knowledge of Emmi Pikler's pedagogy. This community of practice holds two-hour long monthly sessions, which as a result of the four-year collaboration with the author of this article have led to its expanded version in Medialab-Prado, a public institution of international prestige within the arena of digital culture.

The general aim has been to propose an expanded experience, in the sense that it is technologically mediated, promoting the use of open tools and standards of the social web among the members of this community. The idea would be to open the possibilities of dialogue and contemplate new incorporations and educational resources that improve the efficiency of learnings, through the management of networked knowledge, as well as give visibility to its activities and add value to other networks, groups or communities. The design of this experience, as well as its analysis and interpretation, intend to promote a collaborative and participatory work model, in order to incorporate the expanded component or appropriating of Internet's digital public space in different learning scenarios. We shall also point out other conceptual tools that are present in this study, as well as the type of the research questions or procedures that it allows to develop.

\section{a. Research and Procedural Context}

The AMEIGI association encompasses a committed group of preschool and kindergarten education professionals from Madrid that, in addition to their activism and mediating role with the public administration, organize a large number of formative activities and reflective seminars, as well as an annual national congress usually held at the UAM. Part of its members come from, or have collaborated with, social movements for the renewal of pedagogy and the transformation of the education system. Another of the key features of the PAR is related to the agency issues of the participants, placing as a priority the empowerment of the actors involved to create knowledge by understanding their social reality and trying to transform it collectively.

At the start of the 2013-14 school year, the author of this article initiated a collaboration between AMEIGI, the research group "Infancia Contemporánea" of the UAM (of which he was a member) and Mediática - accessible at http://mediatica.co (Mediática, 2016a) - a collective which he founded and that conducts services for the accompanying and experimentation with educational communities that desire to change their digital uses and practices. The aim was to incorporate, develop and research the impact of the expanded component, the mediation of digital technologies and tools of the social web, in the reflective seminar on Pikler's pedagogy that AMEIGI has been promoting for a couple of years with a high level of implication through an intensely participatory practice. The digital uses of the attendees of the meetings were scarce when the innovation project commenced, although there were certain differences that were generally related to age. 
Afterwards, during the 2014-2015 school year, Medialab-Prado - pertaining to the Culture and Sports Area of Madrid's City Council - as an institution dedicated to digital culture included, in response to Mediática's application, the Pikler Seminar as one of its work groups and hosted many of its monthly encounters (figure 1). This municipal space is thought as a citizen laboratory for the production, research and dissemination of cultural projects that explore collaborative ways of experimentation and learning born out of digital networks.

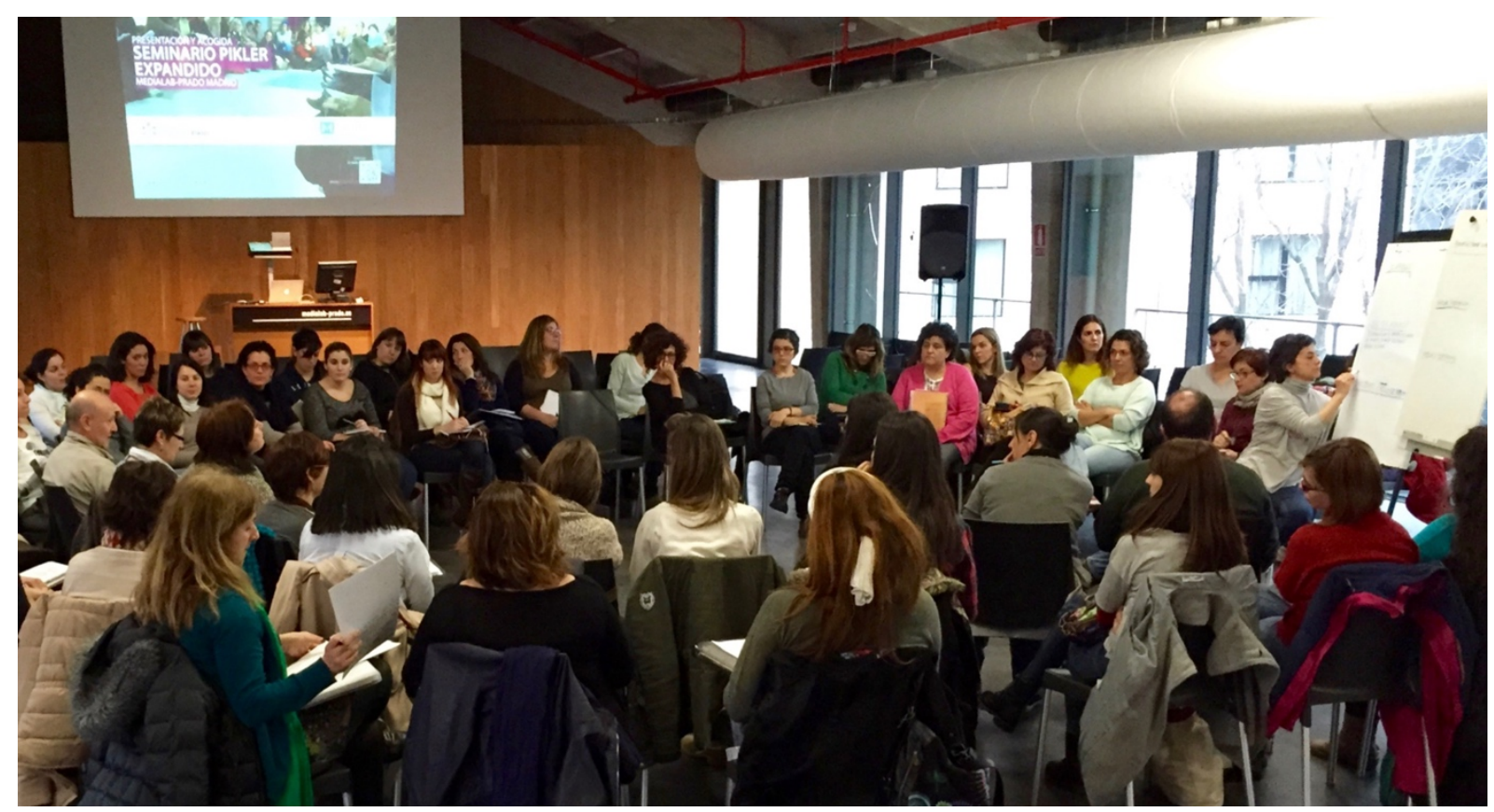

Figure. 1. Monthly encounter of the Pikler Seminar Madrid at Medialab-Prado

The fieldwork that this study gathers has gone on until mid-2017. The structural complexity of participation has allowed us to reach an ample and diverse corpus of data that provides a generous amount of possible analytical approaches. The gathering of data involved a selection of techniques, specially those that followed ethnographic methodologies for the recollection (Wilson \& Peterson, 2002), research and visual analysis (González-Patiño, 2011; Mitchell, 2011; Pink, 2013; Thomson, 2010), public and private digital space ethnography (Horst \& Miller, 2012), participatory observation during work sessions and their video recordings as well as the recordings of other activities, and semi-structured interviews and informal conversations with participants that occupy different positions within the social organization of this community. Likewise, other data was gathered from several complementary sources (informal observations, hub documentation and maintenance, participation in events, etc.).

\section{b. Learning and Teaching by Sharing: Participatory and Digital Learning}

The result that this participatory research project sought was to establish the basis to create a learning community that could be able to autonomously produce its own content and progresses. The approach to the concept of expanded event translated to the open approach of the Pikler Seminar, incorporating the environment of digital networks and resources as a new space to develop its activity. Therefore, the social web holds a prominent place. The online public space, which reinforces the participatory component regardless of its geographical position, is conceived to enable the participants to present and exchange analysis, reflections, research and experiences. 
This innovation in the management of the face-to-face event extends it beyond temporal limits, relying on open formats for its continuation after the initial face-to-face encounters take place.

The organization model is based on the way the network operates (barely lineal or hierarchal). It is highly adaptable, since it offers more efficiency to undertake a great variety of complex situations. In this sense, regarding classical linear visions of knowledge administration, the network can adapt easily to the structure of reality, since it creates groups with common experience to confront situations where shared knowledge is acquired. In sum, the network, as a complex and community system of growth, has a relevant characteristic, which is its capacity to self-organize in as much as it learns to adapt to the cycles of learning situations.

\section{Results: Protocols and Scenarios for Distributed Collaboration}

Once completed the design of the action plan, the intervention, a central issue of this investigation is to analyze the mediation and appropriations that the participants carry out thanks to Internet's digital space. Where, as a community that is learning, they strive to be present and participate in a discourse that they feel identified with as global actors, which suggests common protocols, creating channels that promote collective interaction and production of knowledge, and allows for the processing of relevant information. The strategy to achieve an experiential and expanded event of these characteristics, a seminar that goes beyond face-to-face presence, that goes beyond local and the temporal restrictions, and that invests in the collective production of public knowledge, involved the design, implementation and use of the following functional elements:

- The center node or hub, accessible at http://seminariopikler.com (Mediática, 2016b), is the website that combines participation and communication, created with a content manager (WordPress, which uses open and free code) that works as a repository of contents and resources. It also integrates and supports the social networks and other platforms that have been joined the event and the dynamization of the community (RSS subscription, mailing list, newsletter, etc.).

- A brief manual, or style guide, that offers the framework for the community's common desirable protocols. It includes public documentation with technical and conceptual suggestions and recommendations to improve the quality of participation in this open event.

- Social networks as open invitations to the conversation, motivating contributions and discussions, generating trust, increasing the possibilities for establishing relationships and access between the participants and interested people. Among the platforms with these aims, and each with different objectives, the Pikler Seminar uses Twitter accessible at http://www.twitter.com/seminariopikler, an open Facebook group at http://www.facebook.com/groups/seminariopikler, the Google + profile at http://www.google.com/+seminariopikler and a YouTube channel at http://www.youtube.com/user/piklermadrid for audiovisual content. Currently the use of the following tools is under consideration: LinkedIn (professional network) to enhance discussions; Scribd (social publication), Diigo (shared markers) and Slideshare to publish contents related to the seminar and its dissemination. Likewise, the convenience of using other specialized and vertical platforms, such as Academia.edu or Researchgate.net will be analyzed.

- The dissemination of the events was handled using Google Hangouts, which, in addition to offering the possibility of creating live emissions (streaming) even with remote guests (videoconferences) with a very low cost, integrates and facilitates the work flow 
with other platforms, facilitating the storage and access to the audiovisual content on YouTube after these events take place.

- For the management of the online collaborative work and e-mail list, the group uses a crucial tool for its communication, Mediática's G Suite platform for education (Drive, Groups, Docs, etc.).

- Other issues have been taken into considerations such as those related to responsive design to take advantage of the increasing access possibilities offered by mobile devices (smartphones, tablets, etc.).

It could all be summed up synthesizing the aims of AMEIGI and Mediática as follows: we intend to be present in the digital social space relevant for the participants and those interested in the Pikler Seminar Madrid. Listening and processing valuable information, fostering participation and debate regarding our activity, contributing tools and resources that enable participation and a reflection that goes beyond the celebration of a face-to-face event, and motivating interaction through the promotion of a participatory practice coherent with our style and interests as organizers and collaborators.

\section{a. The Roll of the Moderator}

The operative plan to motivate participation and distributed leadership includes the figure of the moderator of the virtual community, based on the communities of practice approach (Hara, Shachaf, \& Stoerger, 2009; Sanz Martos, 2005). This moderation or participatory consultancy coordinated with the organizing committee implies, among other things, tutelage, monitoring, management, following and dynamization; since the moderator, through a proactive attitude, could have the following duties:

- Presenting, planting and inspiring respect for the frame of the style guide of this open community.

- Listening, following the network, attending not only to the channels that are officially set up, but in search of conversations on the community's area of interest.

- Inspiring, extracting what is relevant in listening and giving it circulation among the participants and the organization.

- Orienting, suggesting and improving the quality of participation applying the common desirable protocols for the communities (codes of action, supervision of folksonomies or social indexations, relationship with leaders of opinion, etc.).

- Identifying leaders, both in and out of the community, prompting the participation or recruiting of people of certain relevance.

- Finding ways of collaboration and enhancing the conversation of the members.

- Responding to queries, proposing additional examples and clarifications.

Through expanded communities it is possible to link the interests of people, their relationships and the achievement of recognition, enjoying an authentic and profound implication in learning. By presenting the case of the Pikler Seminar Madrid to promote and inspire more open learning experiences, communities that rely on collective production of public knowledge, it could be especially interesting to indicate that throughout the process there was a need to reflect on the management of, at least, these elements: 
- Resources (material, contents): in addition to the selection offered by the current version of the Pikler Seminar, other educational materials and resources (modules, objects of learning) were offered freely and openly so anyone could use them.

- Activities: open and mediated by social web applications, in addition to those observed in the face-to-face sessions.

- Participation: an added advantage of this proposal to use open standards, as opposed to closed platforms, is that given the great quantity of services available on the social web, many of them equivalent, allow the negotiation of tools between the members of the community, respecting the most common styles and practices.

- Moderation: a model of moderation close to facilitation and motivation for the learning community, created under the influence of the Seminar, and a distribution of leadership close to the idea of legitimate peripheral participation (Wenger et al., 2002).

- Evaluation: either through the requirement of proof of learning via personal commentaries, proposals of intervention and/or transference of collective final knowledge, the aim would be to undergo a self-evaluation of this learning experience.

\section{b. Learning Trajectories}

Up until recently, in a near past that varies depending on the media inclusions allowed by the different educational institutions or social agents, the contexts of learning practices were based, in most cases, on written culture. The irruption of new audiovisual media, first, and the digital public space, afterwards, marks the beginning of a dizzying process of great semiotic complexity in which media and manners combine around technologies that offer communicative alternatives of great diversity. To this informational multi-modality one should add the condition of integration or convergence of systems, platforms and devices, in order for our alternatives of access, creation and negotiation of meaning to multiply exponentially. To the concept of convergence that we are referring to, which we would describe as a technological type or "device agnosticism" (we are connected regardless of the artifact), we should add another type more relevant to our analytical aims, which we could denominate as cultural convergence, that is related to the change in uses of the media and that according to Jenkins (2008) is located at the base of participatory culture, in virtue of which we cannot easily separate the processes of creation and the dissemination of content.

As has been demonstrated, the participants of the Pikler Seminar appropriate from the expanded experience choosing and creating new trajectories, both textual and participatory. The appropriation and use of the resources and digital space, both public and private, by the community is heterogeneous and for certain educators it implies a radical shift, both in the way they managing information and documents as well as in the way knowledge is created and shared. However, due to the way the expanded allows to compile, distribute and store the materials generated through participation during the face-to-face sessions that take place once a month, we also find interconnections (intertextual links, for instance) among shared reflections that are quite intense.

As shown in figure 2 the analysis of mediation and participatory trajectories do not present a linear structure, or one that follows protocol. On the contrary, the only events that followed a pattern were the face-to face reflective sessions celebrated the last Thursday of every month, from September to July, always at the same time, 5:30 PM. During the early stages, when the group consisted of little more than twenty participants, they met in one of the preschools that was part of the AMEIGI network, Las Nubes, which had a staff that was one of the most experienced and educated in the entire region of Madrid regarding Pikler pedagogy. 


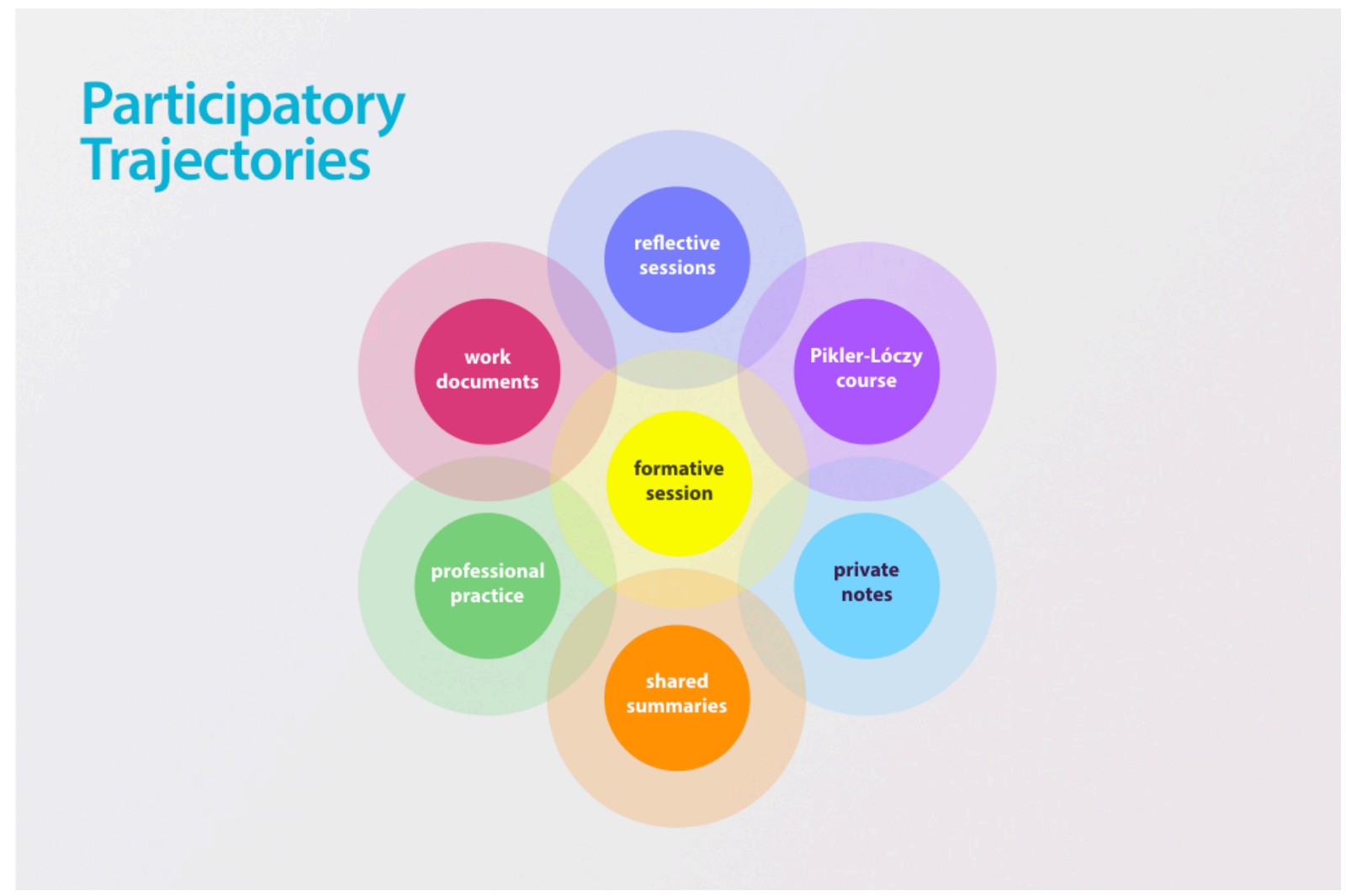

Figure. 2. Mediation and Participatory Trajectories in the Pikler Seminar Madrid Source: Own elaboration (2018)

Afterwards, when the expanded version started to grow as a result of the action research project coordinated by Mediática, the sessions moved Medialab-Prado Madrid, where the participants increased substantially, sometimes reaching more than one hundred. Within those face-to-face sessions one specific type of session started to stand out, the formative session, which usually coincided with the beginning of the course. Each year the session was organized around a specific topic (sphincter control, nutrition, relationship with educators or families, among others) chosen by the participants. To start off the activity that would continue over the following months, an expert of renowned national and international prestige among the educational community interested in Pikler's pedagogy was invited (for instance, Éva Kálló from Pikler-Lóczy Institute from Budapest gave a conference at Medialab-Prado that gathered a large sum of people). As we can see in extract 1, which corresponds with a transcription extracted from the interview with Chelo Fernández (one of the founders of the Pikler Seminar), the process of meaning of the dialogic activity of this learning experience is based on relationships of intertextuality among expert knowledge and teacher knowledge, the latter would incorporate the participants depending on their professional practice (Ernst-Slavit \& Poveda, 2011):

When we invited speakers we felt plugged in, they brought us content, they brought us questions, they created doubt... we always knew that you needed to hook up yearly [...] they give you material to work with, because we didn't have any, we had our practice [...] many times we would say...I do it this way, I don't know if it is right, like saying Pikler is there as what is well done and I, I do this, then we would receive this discharge like the model of what was good, we know that that's good o we think that it is, and then with this material [...] we have a content, a topic on which to move on [...] I see it this way, from 
there on you can do many things, like we did last year... So we have to analyze communications, do our own reading [...] From last year we obtained two documents that were very practical that we can lend and feel totally proud of, where we have the criteria that sustains nutrition [...] in detail according to age, including each phase the children go through.

Extract. 1. Interview with Chelo Fernández, founder of Pikler Seminar Madrid

This network of interconnections between texts, explanations, debates and reflections on the professional practice, in relation to the expert discourse of the speaker, unfolds during the following year thanks to the private notes that, in part, are shared publicly during the monthly encounters in the form of shared summaries. It goes beyond the face-to-face event via a digital platform, using the collaborative work documents. When an educator assists to a Pikler-Lóczy course (which usually take place in the Basque Country or Catalonia) she shares her experience and the resources with the rest of the community, which legitimizes this expansion of identity assuming her expert leadership on this matter. On the other hand, the sessions in Medialab-Prado are streamed live, they also includes remote guests (participating via videoconference and chat messaging). In the central node or hub there is a section dedicated to a multimedia archive with all the contents available in all kinds of format: video, audio, text and all the documents collaboratively created by the community. Lastly, the public digital space of social networks has been incorporated as the scenario for the development, management and communication of the activity; reinforcing participation and widening the possibilities of conversation regardless of geographical location and going beyond temporal limits, creating the possibility of counting with open formats that allow continued participatory learning after the face-to-face encounters, which extends their life after they take place.

\section{Discussion and Conclusions}

Through the analysis of this experience of expanded learning, the Pikler Seminar Madrid has tried to understand the logics of the digital as a form of being and giving sense to the world in which we live (Horst \& Miller, 2012). Where media offers opportunities to connect practices through time and in different scenarios to stimulate located and interest oriented learning. Also, certain methodological issues are singled out and shared, with the intention to help an intervention or inspire the innovation in processes of educational change. At the same time, knowledge is being created from a participatory and transdiciplinary perspective, which specific to our connected society. A search that takes places in the intersection of easily identifiable and recognizable contexts (whether they are institutionalized, formal or informal) and other public and private digital spaces with complex participatory and dynamic structures that follow a consensus and contribute a large part of the corpus of data. In as much as possible, since we are trying to showcase the diversity of trajectories that partake in this community of practice, we have avoided ruptures by basing our work on practices or respecting socio-educational ideologies that are examined during the approximation to the field phase. Although in a general manner, our starting point has been the frame of situated learning and legitimate peripheral participation for the analysis of activity (Lave, 2011). The notion of interpretive community (Borg, 2003; Fish, 2003), related to the interpretation of literary texts, has been particularly relevant for the completion of the analysis of the textual and participatory trajectories that have taken place.

However, we need to acknowledge the invisible barriers of participation that operate even within the most solid forms of participatory culture. It is possible that the people involved in a community fail to recognize ways in which the practices that they have interiorized can become great obstacles 
for someone outside of that community. During certain debates of the Pikler Seminar this was a recurrent issue, especially when there were newcomers (something that was quite frequent during the expanded construction phase, when the number of participants increased fourfold). The community explicitly accepts the diversity of viewpoints; the pedagogical orientation or the socioeducational ideology is independent from a good or bad professional practice if it is reflective. But in a meeting crowded with preschool and kindergarten educators, those who came from schools that did not prioritize the child's autonomy, would end up immersed in a debate on why their schools did not adopt Pikler's pedagogy. A university student that assisted in order to deepen her knowledge of these approaches and that works in one of these schools, went to the extent of reflecting in her personal notes how lost she felt professionally, writing "GOD! I'm a HORRIBLE educator!" (figure 3).

This is not a productive approach in terms of inspiring other professionals to produce educational improvements in schools that, for instance, do not count with certain human or material resources necessary to commit themselves to this pedagogical approach. In fact, this produced quite a few drop outs and was behind the creation of a nucleus that self-proclaimed the legitimacy of their expert knowledge and put an end to a part of the process of construction of meaning based on intertextual relations or, if we turn to issues of more semiotic complexity, taking into account the diversity of trajectories of those invited to the expanded event, the sense of concepts would change from one context to another or from one practice to another, in virtue of the resemiotization process of communicative acts with this kind of multimodal range (Iedema, 2003).

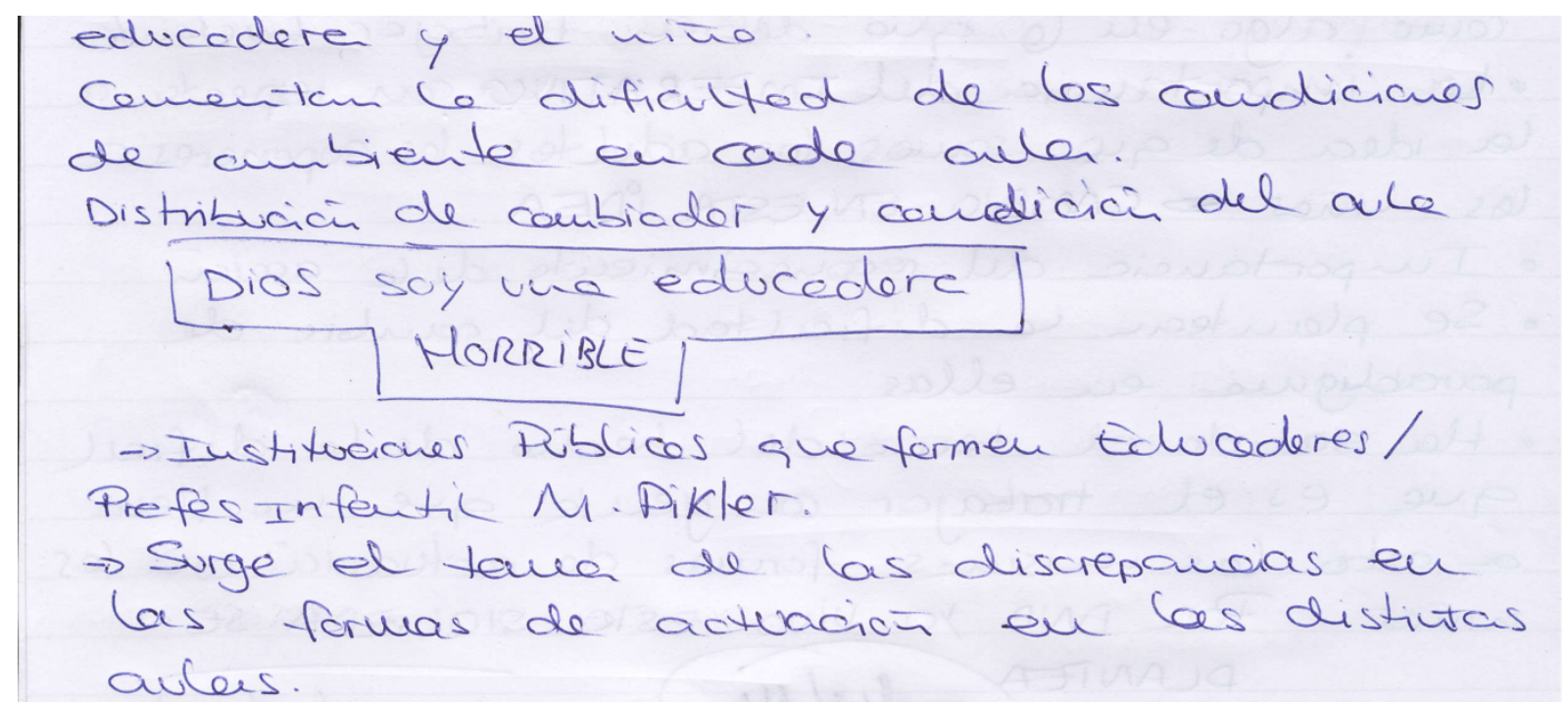

Figure. 3. Private notes written by a participant of the Pikler Seminar

The educators of the Pikler Seminar, or the people who decide to participate in a community to share their interests with the intention of creating knowledge, previously have had different levels of access to certain materials or practices. This reflection that might take us to analyze the barriers to participation, appropriating the digital space of Internet, would be in line with the proposals offered by the program of digital identity funds (González-Patiño \& Esteban-Guitart, 2015) in the sense of promoting the research of cultural funds (artifacts and cultural instruments) and the relevant uses and interests mediated by the digital, with the intention of incorporating them into the learning and participatory practices, which would contribute to their conversion into a significant transforming process, sensitive with the ways of life of the participants. 
Therefore, people can may be motivated or dissuaded to show their identities in certain ways, they can be more or less inclined to express certain interests or desires, and they will have more or less probabilities of wanting to be incorporated into certain specific communities of practice. These communities do not necessarily need to be excluding to become too homogeneous; they can be open and at the same time limit the participation, because the interest that unites them is easier to find depending on cultural and socio-economical antecedents (Jenkins et al., 2015).

The aspiration of this publication, which by far exceeds the modesty of its contribution, is to promote a connected learning that articulates diversity as a guarantee of efficiency and social justice, understanding connected learning as an activity that is situated and central in our current knowledge society (Ito et al., 2013; Kalantzis \& Cope, 2012).

\section{Acknowledgments}

This research project had the initial support of the agreement 0131/2014 signed by UAM with AMEIGI and coordinated by David Poveda. The expanded experience was promoted by AMEIGI with the participation of Mediática and the collaboration of Medialab-Prado. The last phase of analysis has been possible due to the funding received from the project of UAM 0243/2017 whose principal researcher is the author of this paper. Many people have contributed in this initiative, however, the interventions of the participants of the community of practice - the Madrid Pikler Seminar - and its founders, Pilar García and Chelo Fernández, have been especially noteworthy. Finally, my deepest gratitude goes to Blanca Azanza, president of AMEIGI, for her involvement and unconditional support. 


\section{References}

Balcazar, F. E. (2003). Investigación acción participativa (IAP): Aspectos conceptuales y dificultades de implementación. Fundamentos en Humanidades, 4(007-008), 59-77.

Borg, E. (2003). Discourse community. ELT journal, 57(4), 398-400.

Bruner, J. S., \& Palacios, J. (2008). Desarrollo cognitivo y educación (6 ed.). Madrid: Morata.

Carr, N. G. (2011). The shallows: What the internet is doing to our brains. New York, London: W. W. Norton \& Company.

Cobo, C., \& Moravec, J. W. (2011). Aprendizaje invisible. Hacia una nueva ecología de la educación. Barcelona: Laboratori de Mitjans Interactius / Publicacions i Edicions de la Universitat de Barcelona.

Coll, C. (2013). El currículo escolar en el marco de la nueva ecología del aprendizaje. Aula de Innovación Educativa(219), 31-36.

Erickson, F. (2014). Scaling down: A modest proposal for practice-based policy research in teaching. Education Policy Analysis Archives, 22(9), 1-7. doi:http://dx.doi.org/10.14507/epaa.v22n9.2014

Ernst-Slavit, G., \& Poveda, D. (2011). Teacher knowledge and minority students: The potential of saberes docentes. Pedagogies: An International Journal, 6(1), 1-15. doi:10.1080/1554480X.2011.531940

Fish, S. (2003). Is there a text in this class? The authority of interpretive communities. Cambridge, Massachusetts: Harvard University Press.

Gee, J. P. (2010). New digital media and learning as an emerging area and "worked examples" as one way forward. Cambridge, Massachusetts: The MIT Press.

Gee, J. P. (2013). The anti-education era: Creating smarter students through digital learning. New York: Palgrave Macmillan.

González-Patiño, J. (2011). Rutinas de la infancia urbana mediadas por la tecnología: Un análisis visual. Papeles de Trabajo sobre Cultura, Educación y Desarrollo Humano, 7(2), 1-16.

González-Patiño, J., \& Esteban-Guitart, M. (2015). Fondos digitales de conocimiento e identidad: Un análisis etnográfico y visual. Papeles de Trabajo sobre Cultura, Educación y Desarrollo Humano, 11(2), 20-25.

Hara, N., Shachaf, P., \& Stoerger, S. (2009). Online communities of practice typology revisited. Journal of Information Science, 35(6), 740-757. doi:10.1177/0165551509342361

Horst, H. A., \& Miller, D. (2012). Digital anthropology. London, New York: Berg.

Iedema, R. (2003). Multimodality, resemiotization: extending the analysis of discourse as multi-semiotic practice. Visual Communication, 2(1), 29-57. doi:10.1177/1470357203002001751

Ito, M., Gutiérrez, K., Livingstone, S. M., Penuel, B., Rhodes, J., Salen, K., . . Watkins, S. C. (2013). Connected Learning: An Agenda for Research and Design. Irvine, CA: Digital Media and Learning Research Hub.

Jenkins, H. (2008). Convergence culture: La cultura de la convergencia de los medios de comunicación. Barcelona: Paidós.

Jenkins, H., Ford, S., \& Green, J. (2013). Spreadable media: Creating value and meaning in a networked culture. New York, London: New York University Press.

Jenkins, H., Ito, M., \& boyd, d. (2015). Participatory culture in a networked era: A conversation on youth, learning, commerce, and politics. Cambridge, Malden: Polity Press.

Kalantzis, M., \& Cope, B. (2012). New learning: elements of a science of education (2 ed.). New York: Cambridge University Press.

Lave, J. (2011). Apprenticeship in critical ethnographic practice. Chicago: University of Chicago Press.

Lave, J., \& Wenger, E. (1991). Situated learning: legitimate peripheral participation. Cambridge: Cambridge University Press.

Mediática. (2016a). Mediática | Inspiring the new learning for the digital culture. Retrieved from http://mediatica.co 
Mediática. (2016b). Seminario Pikler Madrid | Comunidad dedicada al estudio de la pedagogía Pikler. Retrieved from https://seminariopikler.com

Mitchell, C. (2011). Doing visual research. London: Sage Publications.

Noffke, S. E., \& Somekh, B. (2013). The SAGE handbook of educational action research (1 ed.). Thousand Oaks, CA: SAGE.

Orr, J. E. (1996). Talking about machines: An ethnography of a modern job. Ithaca, NY: Cornell University Press.

Pink, S. (2013). Doing visual ethnography: Images, media, and representation in research (3a ed.). Los Angeles: SAGE.

Reason, P., \& Bradbury, H. (2008). The SAGE handbook of action research: Participative inquiry and practice (2 ed.). London: SAGE.

Regina Frizzo, K. (2008). La investigación acción participante. In E. Saforcada \& J. Castellá Sarriera (Eds.), Enfoques conceptuales y técnicos en psicología comunitaria (1 ed., pp. 151-164). Argentina: Paidós.

Sanz Martos, S. (2005). Comunidades de práctica virtuales: Acceso y uso de contenidos. Revista de Universidad y Sociedad del Conocimiento (RUSC), 2(2), 26-35.

Siemens, G. (2010). Conectivismo: Una teoría de aprendizaje para la era digital. In R. Aparici (Ed.), Conectados en el ciberespacio. Madrid: Universidad Nacional de Educación a Distancia.

Thomson, P. (2010). Doing visual research with children and young people. Abingdon, New York: Routledge.

Van Dijck, J. (2013). The culture of conectivity: A critical history of social media. New York: Oxford University Press.

Wardrop, A., \& Withers, D. M. (2014). The para-academic handbook: A toolkit for making-learning-creatingacting. Bristol: HammerOn Press.

Wenger, E. (2005). Communities of practice: Learning, meaning, and identity. Cambridge: Cambridge University Press.

Wenger, E., McDermott, R., \& Snyder, W. (2002). Cultivating communities of practice: A guide to managing knowledge (1 ed.). Boston: Harvard Business School Press.

Wilson, S. M., \& Peterson, L. C. (2002). The anthropology of online communities. Annual Review of Anthropology, 31(1), 449-467. doi:10.1146/annurev.anthro.31.040402.085436 